\title{
Control of Cs leachability in cementitious binders
}

\author{
HWAI-CHUNG WU, V. C. LI, YUN MOOK LIM, K. F. HAYES, C.C. CHEN
}

Department of Civil and Environmental Engineering, University of Michigan, Ann Arbor, MI 48109-2125 USA

Nuclear waste, including the production of watersoluble radioactive metal atoms, is inevitable from the production of nuclear energy, and presents a great threat to human health and to the environment [1]. Immobilization of radionuclides is usually accomplished, first, by binding the nuclear waste in suitable solid waste forms. Subsequently, these waste forms are stored at a repository site having multiple physical and chemical barriers. During the long period of containment, any contaminant release must be limited to permissible rates. This can be ensured by stabilizing radionuclides in suitable binder phases, and restricting groundwater flow which may transport soluble radioactive species outside of the containment zone.

Although cementitious materials have been actively used as binder and diffusion barriers because of their ease of processing and low cost, the potential for leaching of radionuclides from porous cements has been a major drawback. The leaching behaviour of cemented radioactive waste forms is controlled by the chemical, physical and mechanical properties of the matrix. Usually, the highly alkaline environment within cement precipitates many radwaste species as relatively insoluble salts [2]. However, when soluble species such as Cs are present, high leach rates (low sorption potential) have been reported [3]. Nevertheless, many additives, such as reactive silica, fly ash and natural pozzolan $[2,4]$, have been shown to markedly enhance the sorption of $\mathrm{Cs}$ in cement binders. By addition of glass powder (sodium silicate and phosphoric silicate) into cement, Okamoto et al. [5] found that the leach rate of cesium from a cement-glass package was only one-tenth of that from plain cement. In addition, cement-glass was shown to solidify eight times as much borates (which are commonly present in waste streams) as the plain cement. Thus, by tailoring the chemical constituents of the cement composites, it is possible to reduce the leachability of highly mobile species such as Cs and $\mathrm{Sr}$.

Leaching in nuclear wastes is generally studied as a diffusion-controlled mass transport process [6]. It has been found that micro-fractures, rather than pores in the paste, control the permeability of concrete [7]: In addition to cracking caused by thermal and mechanical loads, cracking in concrete may be generated by shrinkage stresses due to drying or carbonation [8]. Shrinkage cracks are commonly observed and can be minimized by reinforcing with short randomly distributed fibres [9], by addition of shrinkage-reducing admixtures [10], or by maintain- ing a low water content [10]. Crack width can be further reduced by adequate fibre reinforcement, even under severe mechanical loading $[11,12]$. Water penetration in concrete has been shown to be strongly dependent on the crack width of the medium $[13,14]$. Consequently, permeability of cementitious materials can be reduced very significantly by minimizing the crack width or inhibiting crack formation altogether.

Recently, advances in the micromechanics of fibre reinforced brittle matrix composites have led to the creation of engineered cementitious composites (ECC) at the University of Michigan $[15,16]$. The novel properties of ECC include its tensile strainhardening behaviour more like that of steel than concrete. High ductility and tensile strain capacity can significantly reduce the permeability of ECCs. Hence, low leach rates for $\mathrm{Cs}, \mathrm{Sr}$, and $\mathrm{U}$ can be expected. This can lead to binder waste forms or barriers having much greater durability.

A series of preliminary tests have been conducted to examine the concept of reducing radionuclide leachability by controlling crack width using ECC technology, and enhancing sorption by the addition of binder modifiers.

Four types of cementitious materials were prepared: plain mortar, cement paste with silica fume, ECC (paste) with silica fume, and ECC (mortar) with silica fume. Silica fume was added based on its known ability to improve the Cs sorption capacity of cement [2]. Two types of ECCs, a cement paste and a mortar, both reinforced with discontinuous polyethylene fibre (12.7 $\mathrm{mm}$ long, $38 \mu \mathrm{m}$ in diameter), were employed to provide contrast to the leachability of ordinary mortar. These two ECCs were designed for structural applications and have ultimate tensile strain capacity ranging from 3 to $5 \%$ [17]. Table I summarizes the material composition. Non-radioactive $\mathrm{CsCl}$ was used in this study. Cs was selected due to its known high leachability from unmodified cement.

All ingredients were mixed in a small mixer, then cast into cylindrical moulds of diameter $3.8 \mathrm{~cm}$ ( 1.5 inch) and height $3.8 \mathrm{~cm}$ (1.5 inch). Aluminium rods $(1.27 \mathrm{~cm}$ diameter) were fixed in the middle of each cylinder prior to casting. The rods were intended to promote shrinkage cracking in specimens where more severe Cs leaching can be expected due to the greater surface area exposed. The specimens were demoulded after $24 \mathrm{~h}$ curing at room temperature and $50 \%$ relative humidity. Subsequently, the specimens were placed in 11 polyethylene containers filled with $500 \mathrm{ml}$ deionized water. The water 
TABLE I Composition of cementitious materials (by weight)

\begin{tabular}{llllllll}
\hline Material & Cement & SF & Sand & SP & w/c & CsCl $^{1}$ & Fibre $^{2}$ \\
\hline Paste & 1 & 0.1 & - & 0.01 & 0.27 & 0.0034 & - \\
Mortar & 1 & - & $1^{3}$ & - & 0.35 & 0.0034 & - \\
ECC (paste) & 1 & 0.1 & - & 0.01 & 0.27 & 0.0034 & 0.02 \\
ECC (mortar) & 1 & 0.2 & $0.5^{4}$ & 0.05 & 0.35 & 0.0034 & 0.02 \\
\hline
\end{tabular}

Cement: Type I, SF: silica fume, SP: superplasticizer.

${ }^{1}$ ratio of $\mathrm{CsCl}$ to all materials, ${ }^{2}$ volume fraction, ${ }^{3}$ river sand, ${ }^{4} 50-70$ sand (uniformly distributed between sieve sizes 50 and 70 ).

volume to specimen surface area ratio is 10 . At fixed time intervals (every 2 days), the concentration of Cs in the leachate was measured by using atomic absorption spectroscopy. After sampling for analysis, the leachate was totally replaced with fresh deionized water. The test was performed at $25^{\circ} \mathrm{C}$ from 1 day up to 35 days. Three specimens were prepared for each material, with the average value reported here.

The leach rate was calculated as follows [18]:

$$
\text { leaching rate }\left(\mathrm{g} / \mathrm{m}^{2} \text { per day }\right)=\frac{A_{i}}{A_{0}} \frac{M}{S} \frac{1}{\Delta t}
$$

and

$$
\text { cumulative quantity leached }(\mathrm{cm})=\sum \frac{A_{i}}{A_{\mathrm{o}}} \frac{V}{S}
$$

where $A_{i}=$ weight of element $i$ in leachate

$A_{\mathrm{o}}=$ weight of element in original solid sample

$\mathrm{M}=$ mass of solid sample

$\mathrm{S}=$ surface area of solid sample

$\mathrm{V}=$ volume of solid sample

$\Delta t=$ leach interval

The quantity of Cs leached and the leach rate are plotted in Figs 1 and 2, respectively. The total amount of Cs leached at 35 days is greatest in the mortar, followed by the paste, ECC (mortar) and ECC (paste) (Fig. 1). The reductions in total quantity of Cs leached from paste, ECC (mortar) and ECC (paste), compared to the mortar, are $46 \%, 69 \%$ and $71 \%$, respectively. In addition to having the highest Cs leachability, equilibrium was not reached at 35

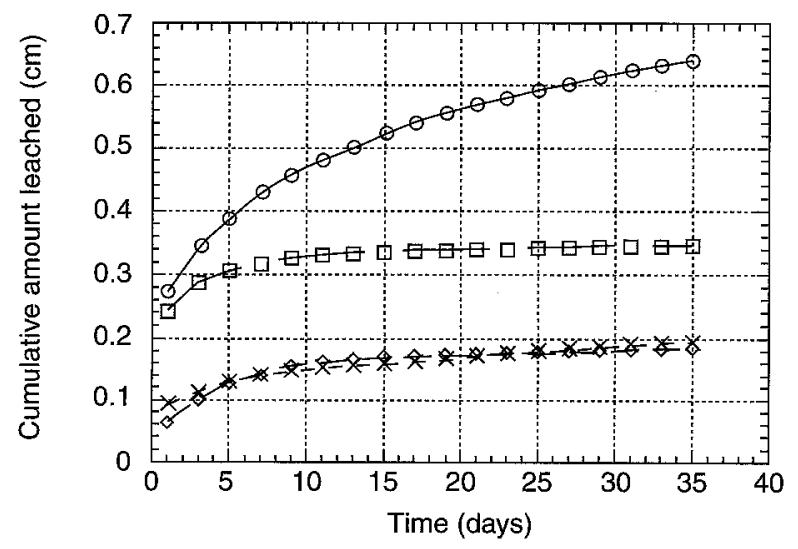

Figure I Leachability of $\mathrm{Cs}$ in various cementitious materials at $25^{\circ} \mathrm{C}$ : $\bigcirc$ mortar; $\square$ paste; $\diamond$ ECC (paste); $\Varangle$ ECC (mortar).

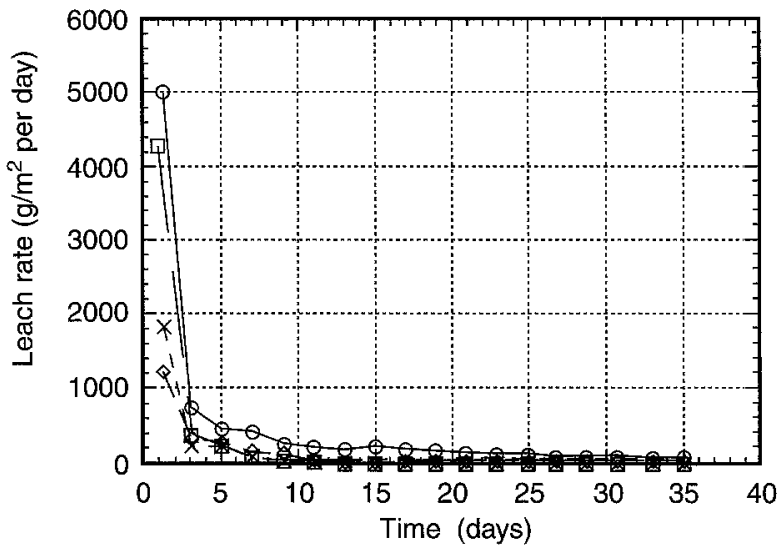

Figure 2 Leach rate of $\mathrm{Cs}$ in various cementitious materials at $25^{\circ} \mathrm{C}$.

days by the mortar specimens. Silica fume proved to be an effective sorbent for $\mathrm{Cs}$, as has been reported previously by McCulloch et al. [2]. Further, ECCs demonstrate an almost $50 \%$ reduction in leaching compared to plain matrix without fibres as a result of reduction in the number of cracks and the crack widths (Fig. 3). The initial washout of Cs from the paste samples is rather high, approaching that of mortar. This is probably caused by the very severe cracking on the paste samples, and hence the much larger surface area exposed to the leachate. The cracking patterns of these four materials are shown in Fig. 3. Only a few very fine cracks were detected on the surface of the mortar specimens, whereas a number of fine cracks were found on the surface of both ECC paste and mortar. It should be emphasized that although the mortar showed the least evidence of cracking, the mortar showed the most severe leaching due to the poor Cs absorption capability of cement and sand and a higher porosity than the paste with silica fume. With the addition of fibres, ECCs (both paste and mortar with silica fume) showed much less cracking and smaller crack widths (6.8 times smaller than that of the plain matrix on average, see Fig. 3), leading to greatly reduced Cs leaching.

Fig. 2 shows leach rate versus time. For all samples, initial leach rates are high, and diminish rapidly. The same phenomenon, resulting from porous structures, was observed when FUETAP concretes (formed under elevated temperatures and pressures) [19], a specially formulated plain concrete for nuclear waste disposal, were leached. The leach rate of FUETAP concrete at 28 days was $48 \mathrm{~g} / \mathrm{m}^{2}$ per day. In this study, leach rates of 102, 9.9, 14.4 and 

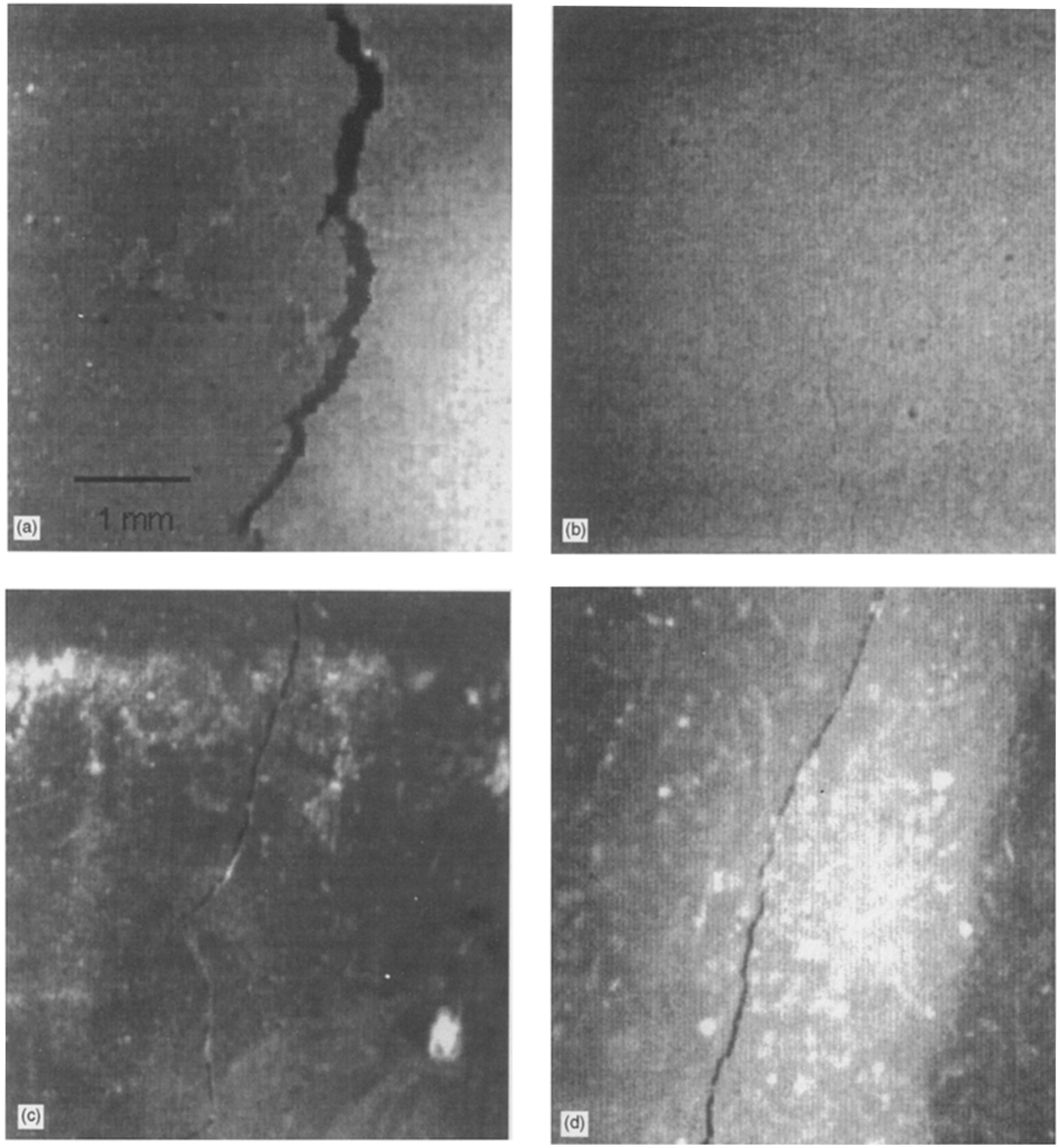

Figure 3 Cracking (computer scanned images) of various cementitious materials used: (a) paste; (b) mortar; (c) ECC (paste); (d) ECC (mortar).

$34.5 \mathrm{~g} / \mathrm{m}^{2}$ per day were obtained for mortar, paste, ECC (paste) and ECC (mortar), respectively, at 28 days. It is not clear why the ECCs showed a higher leach rate than plain paste. The higher leach rate of the ECC mortar compared to the ECC paste is probably due to its higher porosity. These issues should be investigated further. However, it should be noted that our tests were conducted at $25^{\circ} \mathrm{C}$ versus $90{ }^{\circ} \mathrm{C}$ in the FUETAP concrete study, hence a direct comparison is not possible.

It is found from this preliminary test that optimum combinations of fibre reinforcement (such as ECC technology) and matrix modifiers (such as silica fume or clay) can significantly reduce $\mathrm{Cs}$ leachability, Cs being the most mobile water-soluble species in nuclear waste streams. Further reduction in leaching of all radionuclides can be expected when careful consideration is given to matrix modification and selection of reinforcing fibres, since the current version of ECC materials were primarily developed for structural applications.

\section{References}

1. F. S. LAU, "Radioactivity and nuclear waste disposal" (Research Studies Press, England, 1987) pp. 393-398.

2. C. E. McCUllOCH, A. A. RAHMAN, M. J. ANGUS, F. P. GLASSER and R. W. CRAWFORD, in "Advances in ceramics: nuclear waste management, edited by G. G. Wicks and W. A. Ross, (American Ceramic Society, 1984) pp. 113-128.

3. R. W. CRAWFORD, C. McCULLOCH, M. ANGUS, 
F. P. GLASSER and A. A. RAHMAN, Cem. Concr. Res., 14 (1984) 594

4. S. L. HOYLE and M. W. GRUTZECK, Proceedings of Waste Isolation, Technical Programs and Public Education, Vol. 3, University of Arizona, 1986, pp. 491-496.

5. M. OKAMOTO, K. CHINO, T. BABA, T. IZUMIDA, F. KAWAMURA and M. KIKUCHI, Mater. Res. Soc. Symp. Proc. 84, (1987).

6. J. R. CONNER, "Chemical fixation and solidification of hazardous wastes, Van Nostrand Reinhold, New York, 1990).

7. A. T. JAKUBICK and R. KLEIN, in "Coupled processes associated with nuclear waste repositories", edited by ChinFu Tsang (Academic Press, New York, 1987).

8. A. M. NEVILLE and J. J. BROOKS, "Concrete technology" (Longman Scientific, Harlow, Essex, 1987).

9. M. GRZYBOWSKI and S. P. SHAH, ACI Mater. J., 87 (1990) 138.

10. S. P. SHAH, M. E. KARAGULER and M. SARIGAPHUTI, ibid. 89 (1992) 289.

11. H. KRENCHEL and H. STANG, in Proceedings of 2nd International Symposium on Brittle Matrix Composites, edited by A. M. Brandt and I. H. Marshall, 1988, pp. 20-33.

12. V. C. LI, in "Fibre reinforced cement and concrete", edited by R. N. Swamy (Chapman and Hall, London, 1992) pp. $12-30$.

13. J. G. KEER, G. XU and R. FILIP, in "Fibre reinforced cements and concretes-recent developments, edited by R. N. Swamy and B. Barr (Elsevier Applied Science, London, 1989) pp. 592-601.

14. T. TSUKamoto, Darmstadt Concrete, 5 (1990) 215.

15. V. C. LI and H. C. WU, in "Engineering mechanics", edited by L. D. Lutes and J. M. Niedzwecki (ASCE, New York, 1992) pp. 740-743.

16. V. C, LI and T. HASHIDA, in "Fracture mechanics of concrete structures", edited by Z. P. Bazant (Elsevier Applied Science, London, 1992) pp. 526-535.

17. V. C. LI, D. K. MISHRA and H. C. WU, RILEM J. Materials and Structures 28 (1995) 586.

18. M. W. BARNES, B. E. SCHEETZ, L. D. WAKELEY, S. D. ATKINSON and D. M. ROY, in "Scientific basis for nuclear waste management", edited by S. V. Topp (NorthHolland, New York, 1982) pp. 147-154.

19. L. R. DOLE, J. G. MOORE, G. C. ROGERS, G. A. WEST, H. E. DEVANEY, M. T. MORGAN, E. W. MCDANIEL and J. H. KESSLER, in "Scientific basis for nuclear waste management", edited by S. V. Topp (Elsevier, New York, 1982).

Received 16 August 1994

and accepted 28 October 1994 